\title{
Erythropoietin after Focal Cerebral Ischemia Activates the Janus Kinase-Signal Transducer and Activator of Transcription Signaling Pathway and Improves Brain Injury in Postnatal Day 7 Rats
}

\author{
AUGUSTO SOLA, MARTA ROGIDO, BEN H. LEE, TOM GENETTA, AND TONG-CHUN WEN \\ Division of Neonatal-Perinatal Medicine, Department of Pediatrics, Emory University School of Medicine, \\ Atlanta, Georgia 30322
}

\begin{abstract}
Erythropoietin (Epo) plays a central role in erythropoiesis but also has neuroprotective properties. Recently, Epo-related neuroprotective studies used a hypoxic-ischemic neonatal model, which is different from focal stroke, a frequent cause of neonatal brain injury. We report on the effects of Epo treatment given after focal stroke and its potential neuroprotective mechanisms in postnatal day 7 rats with focal cerebral ischemia (FCI) achieved by occlusion of the middle cerebral artery. The experimental groups included sham operation, FCI plus vehicle, and FCI plus Epo. In the Epo-treated group, pups received a single intraperitoneal injection of $1000 \mathrm{U} / \mathrm{kg} 15 \mathrm{~min}$ after FCI or three injections of 100,1000 , or $5000 \mathrm{U} / \mathrm{kg}$, starting at $15 \mathrm{~min}$ and repeated at 1 and $2 \mathrm{~d}$ after FCI. Epo treatment produced significant reductions in the mean infarct area and volume at 1 and $3 \mathrm{~d}$ after FCI, demonstrated by 2,3,5-triphenyltetrazolium chloride staining. Terminal deoxynucleotidyltransferase-mediated 2'-deoxyuridine 5'-triphosphate-biotin nick end labeling (TUNEL) staining showed a markedly reduced number of TUNEL-positive cells in the Epo-treated group when compared with the vehicle control $3 \mathrm{~d}$ after FCI $(p<0.01)$. The most effective dose after FCI was $1000 \mathrm{U} / \mathrm{kg}$ for $3 \mathrm{~d}$. Immunoanalyses showed that Epo induced a significant increase in phosphorylated Janus kinase 2 and signal
\end{abstract}

\section{ABSTRACT}

transducer and activator of transcription-5 expressions at 1 and $3 \mathrm{~d}$ and up-regulated Bcl-xL expression by $24 \mathrm{~h}$ after FCI but did not affect Epo receptor or NF- $\kappa \mathrm{B}$ expression. In conclusion, Epo given after FCI in neonatal rats provides significant neuroprotection, mediated possibly by activation of the Janus kinasesignal transducer and activator of transcription-Bcl-xL signaling pathways. (Pediatr Res 57: 481-487, 2005)

CCA, common carotid artery

\section{Abbreviations}

ECA, external carotid artery

Epo, erythropoietin

EpoR, Epo receptor

FCI, focal cerebral ischemia

ICA, internal carotid artery

IHC, immunohistochemistry

Jak2, Janus kinase-2

MCA, middle cerebral artery

Stat5, signal transducer and activator of transcription-5

TTC, 2,3,5-triphenyltetrazolium chloride;

TUNEL, terminal deoxynucleotidyltransferase-mediated

2'-deoxyuridine 5'-triphosphate-biotin nick end labeling
Erythropoietin (Epo), a glycoproteic hormone produced by the kidney, not only affects the hematopoietic system but also exerts a multifunctional trophic influence on the general homeostasis of the entire organism $(1,2)$. The recent discovery of a specific Epo receptor (EpoR) in the CNS $(1,3)$ has led to investigations in the neurotrophic and neuroprotective effects of Epo on the developing brain. In vitro studies have shown

Received June 23, 2004; accepted September 3, 2004.

Correspondence: Tong-Chun Wen, Ph.D., Division of Neonatal-Perinatal Medicine, Department of Pediatrics, Emory University School of Medicine, 2040 Ridgewood Drive, Atlanta, GA 30322; e-mail address: Tong_wen@oz.ped.emory.edu.

This study was supported in part by grants for scientific research from the Children's Research Center (T.C.W.) and the Goddard Scholarship (A.S.), Emory University (Atlanta, GA).

DOI: 10.1203/01.PDR.0000155760.88664.06 that Epo protects primary cultured neurons against injuries induced by glutamate deprivation, hypoxia, glucose, kainic acid, or serum (4-8). Moreover, in vivo studies demonstrate that Epo attenuates cerebral ischemic damage in adult gerbils, rats, and mice $(4,6,8-10)$.

In neonatal rat models, Epo prevents intrauterine ischemiareperfusion- or $\mathrm{N}$-methyl-D-aspartate receptor antagonistinduced brain injury $(11,12)$ and reduces brain injury in a hypoxic-ischemic model of the postnatal day 7 (P7) rat $(13,14)$. The latter neonatal rat model requires both unilateral carotid artery ligation and systemic hypoxia $(15,16)$ but does not accurately reproduce the pathogenesis of focal stroke in human neonates. Recent epidemiologic studies suggest that the incidence of neonatal focal cerebral ischemia (FCI) is higher than 
previously recognized (17-19) and in fact may be more prevalent than global cerebral ischemia from systemic asphyxia (18). Therefore, it is critically important to evaluate the effects of Epo on focal brain injury by using an appropriate neonatal FCI model.

Epo and its receptor have been shown to play a crucial role in neuronal survival and recovery $(1,3)$. Numerous pieces of evidence indicate that Epo and its receptor are expressed in both neonatal and adult brains (1-3) and are up-regulated by hypoxia and ischemia (6), and Epo concentration is significantly increased in cerebrospinal fluid of asphyxiated human neonates (20). Recently, using a modified permanent FCI model in the P7 rat (21), we found that FCI induces a significant increase in EpoR expression in the neonatal rat brain, and EpoR was expressed on neurons, microglia/macrophage, and endothelium of blood vessels in the ischemic hemisphere $24 \mathrm{~h}$ after FCI (22). Furthermore, terminal deoxynucleotidyltransferase-mediated 2'-deoxyuridine 5'-triphosphate-biotin nick end labeling (TUNEL) staining indicated that nearly half of EpoR-positive cells were also TUNEL positive in the ischemic cortex $24 \mathrm{~h}$ after FCI (22). Although TUNEL staining is not a specific test for detecting cell apoptosis and a supplemental test such as detecting caspase activation is required to confirm whether TUNEL-positive cells undergo apoptosis, our results suggest that EpoR-positive cells may undergo apoptosis-like cell death in ischemic areas. Given these findings, we theorize that endogenous Epo is produced by certain populations of cells in the brain and that under normal conditions, neuronal survival in the developing brain is maintained, at least in part, by endogenous Epo. We further speculate that with significant ischemic stress to the brain, the endogenous Epo pool may be insufficient for neuronal homeostasis and protection and that the relative insufficiency of Epo during such periods of ischemic stress then may trigger neuronal apoptosis. Therefore, we hypothesized that provision of exogenous Epo after FCI mitigates FCI-induced brain injury.

It is well known that in nonneuronal cells, the effects of Epo are mediated by its receptor, which subsequently activates Janus kinase 2 (Jak2), leading to tyrosine phosphorylation of the signal transducer and activator of transcription 5 (Stat5) and the up-regulation of antiapoptotic genes $(23,24)$. Recent data have shown that Jak2-Stat5 were expressed in the various brain regions during embryonic and postnatal stages, suggesting that Jak2-Stat5 may be involved in brain development (23). In cultured neuronal cells, Epo has been demonstrated to protect cerebrocortical neurons from excitotoxic- and nitric oxide-induced damage by triggering cross-talk between Jak2 and nuclear factor- $\kappa \mathrm{B}(\mathrm{NF}-\kappa \mathrm{B})$ signaling pathways (25). $\mathrm{NF}-\kappa \mathrm{B}$ has been shown to up-regulate transcription of other antiapoptotic proteins such as inhibitors of apoptosis protein (XIAP and c-IAP), which block activation of specific celldeath caspases and subsequent apoptosis (26). Moreover, Epo has further been found to significantly up-regulate expression of pro-survival Bcl-xL mRNA and protein in the ischemic hippocampal CA1 field of adult gerbils, compared with vehicle treatment (10). Bcl-xL has been shown to suppress apoptosis in part by blocking the release of cytochrome $\mathrm{c}$ from mitochondria, which is a critical step in the activation of the caspase protease cascade (27). However, it is not known whether these events also occur in neonatal brains with FCI.

Given this background evidence and our hypothesis, our study aims were to investigate the effects of Epo on brain injury induced by FCI in neonatal rats and some of the potential intracellular mechanisms by which Epo may prevent neonatal stroke-induced brain injury, specifically evaluating the effects of Epo on the expression of EpoR, phosphorylated Jak2 (p-Jak2) and Stat5 (p-Stat5), and the antiapoptotic genes $\mathrm{Bcl}-\mathrm{xL}$ and $\mathrm{NF}-\kappa \mathrm{B}$ in neonatal rat brains after focal ischemic insult.

\section{METHODS}

Animals. Timed pregnant Sprague-Dawley rats that were carrying 18-d-old fetuses (E18) were purchased from Charles River Laboratories (Wilmington, MA). Pregnant dams were housed in a temperature- and light-controlled animal care facility and given food and water ad libitum. All animal research was approved by the Emory University Institutional Animal Care Committee and performed in accordance with National Institutes of Health animal care guidelines.

FCI model. To produce permanent FCI, we used a modified intraluminal catheter technique to occlude the middle cerebral artery (MCA) in the P7 rat pups, as we have previously described (21). Briefly, each pup was weighed, anesthetized with $2 \%$ isofluorane, and immobilized in a supine position. Under an operative microscope, the left common carotid artery (CCA), the external carotid artery (ECA), and the internal carotid artery (ICA) were separated from adjacent veins and nerves. After ligation of the CCA and ECA, a suture embolus distally coated with silicone resin (using a size appropriate for the pup's body weight) was inserted through a small incision on the CCA just proximal to the CCA-ECA-ICA junction. The suture embolus then was advanced $7-8 \mathrm{~mm}$ so that its tip effectively occluded the MCA. During the operation, the pup's body temperature was monitored continuously using a rectal temperature probe, and euthermia was maintained with the assistance of an overhead heating lamp. During recovery from anesthesia, the pups were kept in a chamber at room air with an environmental temperature of $37^{\circ} \mathrm{C}$ for $15 \mathrm{~min}$ and then returned to their dams. Sham operation involved the same ventral neck incision with dissection of the pertinent vessels but without insertion of a suture embolus.

Experimental groups and treatment with Epo and vehicle. The 140 pups for this study were divided into three groups: sham-operated plus vehicle $(n=$ $30)$, FCI plus vehicle $(n=45)$, and FCI plus Epo $(n=65)$. Recombinant human Epo (4000 U/mL; Amgen Inc., Thousand Oaks, CA) was diluted in a vehicle of $0.01 \mathrm{M}$ PBS (pH 7.4) and $0.1 \%$ BSA to a final concentration of 80 $\mathrm{U} / \mathrm{mL}$. The experimental schedule is shown in Fig. 1. For the studies performed $1 \mathrm{~d}$ after FCI, the pups received a single intraperitoneal injection of either Epo at $1000 \mathrm{U} / \mathrm{kg}$ or vehicle $15 \mathrm{~min}$ after FCI ( $n=13$ pups in each group). For the analyses and studies performed at 3 and $7 \mathrm{~d}$ after FCI, 52 different pups received their first Epo injection 15 min after FCI and then two additional injections once a day for $2 \mathrm{~d}$ at 100,1000 , or $5000 \mathrm{U} / \mathrm{kg}$ each dose. A comparison FCI placebo control group $(n=39)$ received injections of the vehicle at the same volume and schedule as the Epo group. The sham-operated group received only vehicle injection as normal control. The Epo dose and the schedule of administration were chosen according to previous protocols that evaluated the drug in a hypoxic-ischemic model in P7 rat pups $(13,14,28)$. The treatment groups were randomly assigned, and the investigators who evaluated outcomes were blinded to the treatment received.

Measurement of infarct area and volume. For determining the infarct area and volume, 2,3,5-triphenyltetrazolium chloride (TTC) staining was performed after the rat pups were anesthetized with pentobarbital and decapitated at $1 \mathrm{~d}$

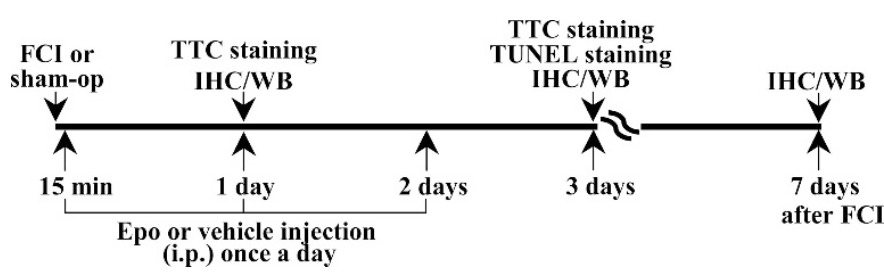

Figure 1. Timeline of the experimental design. WB, Western blot. 
( $n=5$ for $1000 \mathrm{U} / \mathrm{kg}$ of Epo- or vehicle-treated FCI group) and at $3 \mathrm{~d}(n=$ 10 for 100,1000 , or $5000 \mathrm{U} / \mathrm{kg}$ of Epo- or vehicle-treated FCI group) after FCI. Their brains were harvested and coronally sectioned into five 2-mm slices, which then were incubated in a $1 \%$ TTC solution at $37^{\circ} \mathrm{C}$ for $20 \mathrm{~min}$ and fixed in $10 \%$ buffered formalin at $4^{\circ} \mathrm{C}$ overnight. An investigator who was blinded to the treatment group obtained photographs of the sections with a digita camera and measured the infarct area using Windows Image $\mathrm{J}$ (similar to NIH Image). The total infarct volume was calculated as the sum of the infarct areas from the 2-mm-thick continuous coronal sections.

In situ detection of DNA fragmentation. For estimating the number of degenerating cells $3 \mathrm{~d}$ after FCI, TUNEL staining was conducted using an ApopTag peroxidase in situ apoptosis detection kit (Serologicals, Norcross, GA). The sham-operated $(n=6)$ and FCI ( $n=6$ for $1000 \mathrm{U} / \mathrm{kg}$ of Epo- or vehicle-treated animals) pups were anesthetized with pentobarbital and transcardially perfused with $4 \%$ paraformaldehyde $3 \mathrm{~d}$ after operation. Four seria coronal sections, including the dorsal hippocampus $(1.0-1.12 \mathrm{~mm}$ posterior to the bregma) were processed for TUNEL staining (29). Briefly, the sections were incubated 1) in a mixture of terminal deoxynucleotidyltransferase and reaction buffer that contained digoxigenin-dUTP-biotin in a humidified chamber for $1 \mathrm{~h}$ at $37^{\circ} \mathrm{C}, 2$ ) incubated with anti-digoxigenin peroxidase for $1 \mathrm{~h}$ at room temperature, and 3 ) exposed to $0.05 \%$ diaminobenzidine and $0.02 \%$ hydrogen peroxide.

Immunohistochemistry analysis of EpoR. The sham-operated or FCI animals with or without Epo (1000 U/kg) injection were anesthetized with pentobarbital and perfused transcardially with $4 \%$ paraformaldehyde at 1,3 , and $7 \mathrm{~d}$ after operation ( $n=4$ for each time point in each group). The brains were excised and immersed overnight in $0.1 \mathrm{M}$ phosphate buffer $(\mathrm{pH} 7.4)$ that contained $30 \%$ sucrose at $4^{\circ} \mathrm{C}$. Four serial coronal sections $30 \mu \mathrm{m}$ thick at the same level of the dorsal hippocampus for TUNEL staining as described above were cut with a cryostat and processed for immunohistochemistry (IHC) with an affinity-purified rabbit antibody against EpoR (Santa Cruz Biotechnology, Santa Cruz, CA). In brief, the sections were 1) washed with 0.1 M PBS for 30 min; 2) incubated in $3 \%$ hydrogen peroxide for $10 \mathrm{~min}$ to quench endogenous peroxidase; 3 ) incubated in blocking solution that contained $10 \%$ normal goat serum, $0.3 \%$ Triton $\mathrm{X}-100$, and $0.1 \%$ BSA in PBS for $1 \mathrm{~h}$ at room temperature 4 ) incubated with the primary antibody $(1: 100)$ diluted with PBS that contained $1 \%$ normal goat serum and $0.3 \%$ Triton $\mathrm{X}-100$ for $48 \mathrm{~h}$ at $4{ }^{\circ} \mathrm{C}$; and 5 ) incubated with FITC-conjugated anti-rabbit IgG (Sigma Chemical Co., St. Louis, MO) for $2 \mathrm{~h}$. Control immunoreactions excluded the incubation of the first antibody.

Counting TUNEL- or EpoR-positive cells. An investigator who was blinded to the treatment group counted TUNEL- or EpoR-positive cells in the left cortex of the sham-operated or FCI animals with or without Epo treatment in the four serial coronal sections. The mean number of positive cells was calculated for each section in each animal.

Western blot analysis of EpoR, p-Jak2, p-Stat5, Bcl-xL, or NF-кB. Homogenates of the cortices were obtained from the sham-operated and FCI animals with or without Epo (1000 U/kg) injection at 1, 3, and $7 \mathrm{~d}$ after operation ( $n=4$ for each time point in each group). They were solubilized in a sample solution that contained $2 \mathrm{mM}$ EGTA, $0.01 \mathrm{mM}$ phenylmethane sulfonyl fluoride, and 2\% SDS. An equal amount of protein $(40 \mu \mathrm{g})$ in the homogenates was electrophoresed in individual lanes using $10 \%$ polyacrylamide gel in the Laemmli's buffer system (30). Protein concentration was determined by BCA protein assay reagent (Pierce Chemical Co., Rockford, IL) with BSA as a standard. The electrophoretic bands were transferred to nitrocellulose sheets (31) and immunoblotted with an antibody of EpoR (1:100), p-Jak2 (1:200), p-Stat5 (1:200), Bcl-xL (1:200), or NF- $\kappa$ B (1:100). These primary antibodies were purchased from Santa Cruz Biotechnology. Antirabbit IgG coupled with alkaline phosphatase (Promega, Madison, WI) was used for the second immunoreaction. The immunoreactive bands were visualized with nitrotetrazolium blue chloride and 5-bromo-4-chloro-3-indolyl phosphate as described elsewhere (32). Prestained molecular weight markers were purchased from Bio-Rad Laboratories (Richmond, CA) and used to monitor the separation of proteins while electrophoresis was in progress. The Western blot analyses were repeated four times. For quantitative evaluation, the immunoreactive bands were subjected to densitometric analysis with a combination of Adobe Photoshop and the Windows Image $(29,33)$

Statistical analysis. The data of each group are summarized as their mean \pm SD. The two-tailed Mann-Whitney $U$ test was used to evaluate differences in mean infarct area, volume, and numbers of TUNEL-positive cells between Epo- and vehicle-treated pups. Statistical analyses for the data of IHC and Western blot were conducted using ANOVA followed by Fisher's post hoc test. Statistical significance was set at 0.05

\section{RESULTS}

Survival and body weight. All pups that underwent either sham operation or FCI survived to the end of the study period. However, pups that underwent FCI had a body weight that was significantly lower than that of the sham-operated pups $3 \mathrm{~d}$ after FCI (Epo-treated group: $16.5 \pm 0.8 \mathrm{~g}$; vehicle-treated FCI group: $14.0 \pm 1.8 \mathrm{~g}, p=0.8$; sham-operated group: $20.0 \pm$ $1.0 \mathrm{~g} ; p<0.05)$.

Effects of Epo on infarct area and volume. TTC staining revealed a reproducible infarct area in the hemisphere ipsilateral to the MCA occlusion in vehicle-treated FCI pups at 1 and $3 \mathrm{~d}$ after FCI. The infarct area was demonstrated by a lack of TTC staining and a "pale-white" color (Fig. 2A). In comparison, TTC staining of the contralateral hemisphere showed no evidence of infarction or appreciable injury in vehicle- or Epo-treated FCI pups, demonstrated by a deep red stain of cortical tissue (Fig. $2 A$ and $B$ ). One dose of Epo at $1000 \mathrm{U} / \mathrm{kg}$ after FCI significantly reduced the ipsilateral infarct area at the levels irrigated by the MCA by $1 \mathrm{~d}$ after FCI (Fig. 3A). A significant change was also observed $3 \mathrm{~d}$ after FCI, with three doses of Epo (Figs. $2 B$ and $4 A$ ). Epo treatment also reduced significantly the infarct volume (Figs. $3 B$ and $4 B$ ) compared with the vehicle-treated FCI group. Striking, $3 \mathrm{~d}$ after FCI, there was no evidence of infarction in the brains of three of 10 pups that were treated with three doses of Epo $(1000 \mathrm{U} / \mathrm{kg})$ after FCI (Fig. 2B). The mean infarct area and volume in the vehicle-treated FCI group $3 \mathrm{~d}$ after FCI were $64.8 \pm 3.2$ and $129.6 \pm 6.5 \mathrm{~mm}^{3}$, respectively (Fig. $4 A$ and $B$ ). Epo treatment significantly reduced the mean infarct area and volume $3 \mathrm{~d}$ after FCI in a dose-dependent manner (Fig. 4). The most effective Epo dose in this experimental protocol was 1000 $\mathrm{U} / \mathrm{kg}$, causing a $40 \%$ reduction in the mean infarct area $(24.5$ $\left.\pm 5.4 \mathrm{~mm}^{2} ; \mathrm{U}=0.0, p<0.001\right)$ and in volume $(48.9 \pm 10.8$ $\left.\mathrm{mm}^{3} ; \mathrm{U}=0.0, p<0.001\right) 3 \mathrm{~d}$ after FCI when compared with vehicle-treated FCI pups (Fig. $4 A$ and $B$ ).

Effects of Epo on the number of TUNEL-positive cells in the ischemic cortex. Few TUNEL-positive cells were detected

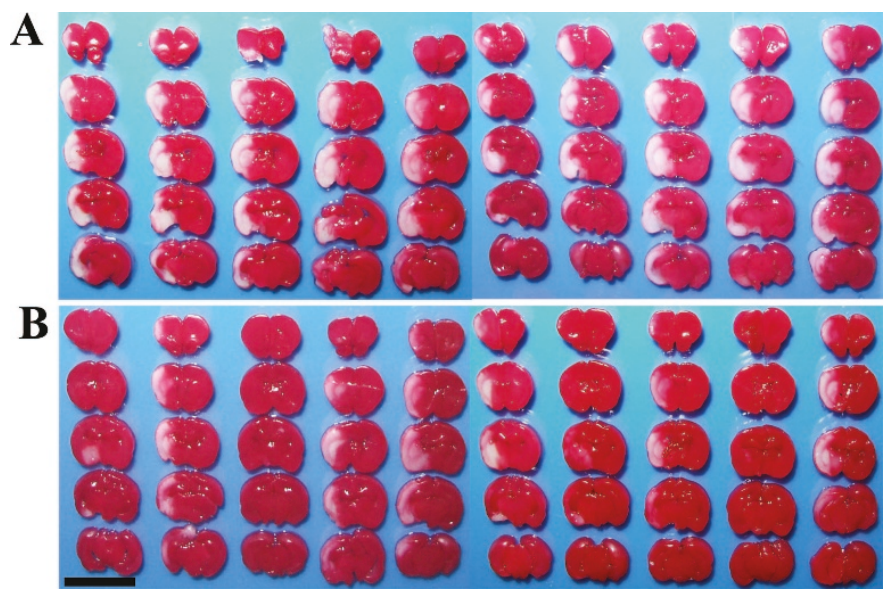

Figure 2. TTC-stained coronal sections $3 \mathrm{~d}$ after FCI. (A) Control (vehicletreated FCI). (B) Epo at $1000 \mathrm{U} / \mathrm{kg}$. A reproducible infarct area was detected in the hemisphere ipsilateral to FCI in the pups that were treated with vehicle, resulting in a "pale-white" infarction color $(A)$. The infarct area was markedly reduced in the Epo-treated group $(B)$. Bar $=1.2 \mathrm{~cm}$. 

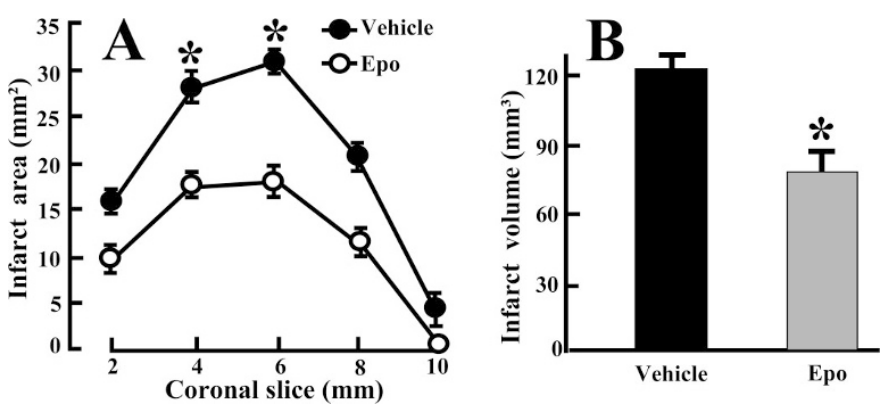

Figure 3. Effects of one dose of Epo at $1000 \mathrm{U} / \mathrm{kg}$ on the infarct area $(A)$ and volume $(B) 1 \mathrm{~d}$ after FCI. Data obtained from measuring the infarcted areas in the TTC-stained coronal sections. Epo significantly reduced the infarct area at the levels irrigated by the MCA $(A)$ and also the infarct volume $(B)$. Values are mean $\pm \mathrm{SD} ; n=5$ for each group; $* p<0.001$.
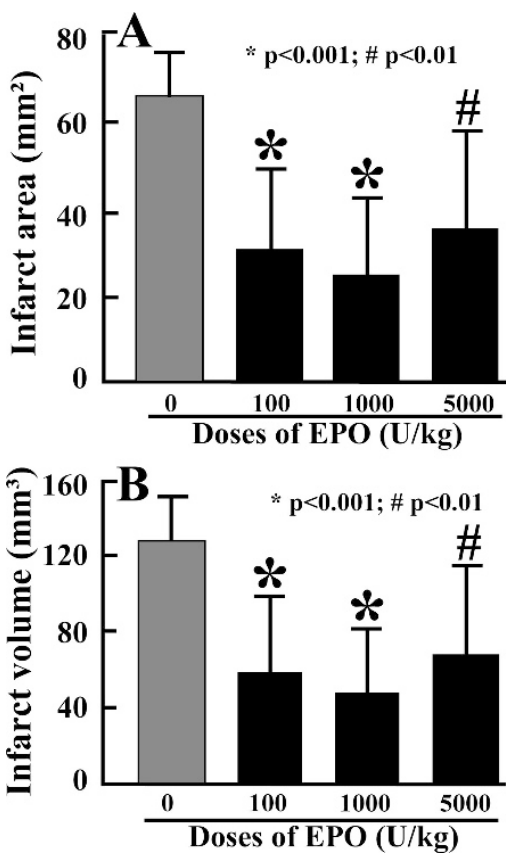

Figure 4. Effects of different doses of Epo on the infarct area $(A)$ and volume (B) $3 \mathrm{~d}$ after FCI. Epo significantly reduced the infarct area and volume in a dose-dependent manner. Each bar represents mean $\pm \mathrm{SD} ; n=10$ for each group; $* p<0.001 ; \# p<0.01$.

in the cortex of sham-operated animals (Fig. 5A), with a mean number of TUNEL-positive cells of $53.0 \pm 13.8$ cells/section (Fig. 5D). FCI induced a significant increase in the number of TUNEL-positive cells in the cortex of the vehicle-treated FCI group (Fig. $5 B$ and $D$ ). Epo treatment after FCI significantly attenuated this (Fig. $5 C$ and $D$ ). Among the pups that underwent FCI, the number of TUNEL-positive cells in the cortex of vehicle-treated rats increased nearly 10-fold (511.9 \pm 39.2 cells/section) $3 \mathrm{~d}$ after FCI (Fig. $5 B$ and $D$ ), compared with the sham-operated pups $(\mathrm{U}=0.0, p<0.001)$. Epo treatment after FCI (three doses at $1000 \mathrm{U} / \mathrm{kg}$ each) significantly reduced the number of TUNEL-positive cells $(132.7 \pm 24.3$ cells/sections) in the ischemic cortex compared with the vehicle-treated FCI pups ( $\mathrm{U}=1.0, p<0.05$; Fig. $5 C$ and $D$ ).

Effects of Epo treatment on EpoR expression in the ischemic cortex. Assuming that intraperitoneally administered Epo penetrates to the ischemic hemisphere to rescue ischemic cells

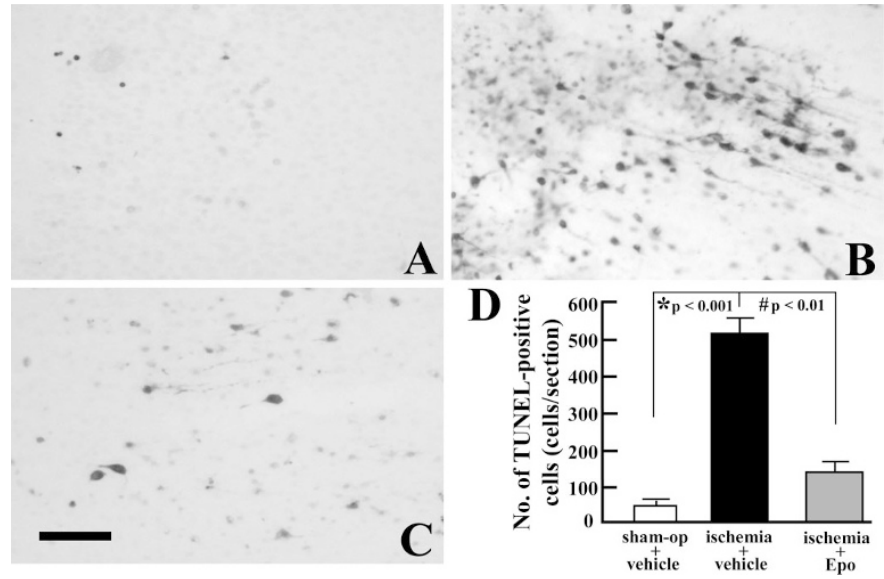

Figure 5. Effect of three Epo doses (1000 U/kg each) on number of TUNEL-positive cells $3 \mathrm{~d}$ after FCI. $(A-C)$ Photomicrographs of TUNELpositive cells in the cortex of sham-operated $(A)$, vehicle-treated FCI $(B)$, or Epo-treated animals $(C)$. $(D)$ Number of TUNEL-positive cells in coronal sections at the level of the dorsal hippocampus. Each bar represents mean \pm $\mathrm{SD} ; * p<0.001$ for FCI $v s$ sham-operated; $\# p<0.01$ for Epo- $v s$ vehicletreated FCI groups ( $n=6$ for each group). Bar $=50 \mu \mathrm{m}$.

via activation of local EpoR, we investigated whether Epo treatment altered EpoR expression in the ischemic cortex from 1 to $7 \mathrm{~d}$ after FCI. IHC analysis $1 \mathrm{~d}$ after FCI showed that FCI caused a significant increase in the number of EpoR-positive cells in the ischemic cortex of FCI rats that were treated with vehicle (Fig. $6 A$ and $H$ ), compared with the sham-operated animals (Fig. $6 G$ and $H$; $* p<0.01$, tested by ANOVA followed by Fisher's post hoc test). This was consistent with our previously reported findings (21). Thereafter, at 3 and $7 \mathrm{~d}$ after FCI, this enhanced EpoR immunoreactivity declined to the level of sham-operated animals (Fig. $6 C, E$, and $H$ ). Epo treatment had no significant influence on EpoR expression in the ischemic cortex $(p>0.05$; Fig. $6 H)$. The number of EpoR-positive cells was similar in the Epo-treated group (1000 $\mathrm{U} / \mathrm{kg}$; Fig. $6 B, D, F$, and $H$ ) and in the vehicle-treated FCI group (Fig. $6 A, C, E$, and $H$ ) from 1 to $7 \mathrm{~d}$ after FCI. These findings were verified by subsequent Western blot analysis (Figs. 7 and $8 A$ ).

Effects of Epo treatment on p-Jak2, p-Stat5, Bcl-xL, or $N F-\kappa B$ expression in the ischemic cortex. Western blot analysis showed a distinct constitutive expression of EpoR, p-Jak2, $\mathrm{p}$-Stat5, Bcl-xL, or NF- $\kappa \mathrm{B}$ in the cortex of sham-operated rats (Fig. 7, lane 1). In the vehicle-treated FCI group, FCI caused significant increases in EpoR expressions at $1 \mathrm{~d}$ (Fig. 7 lane 2; Fig. 8A) and also in Bcl-xL expression at $3 \mathrm{~d}$ (Fig. 7, lane 4; Fig. $8 D$ ) but caused marked declines in p-Jak2 and p-Stat5 expressions from 1 to $7 \mathrm{~d}$ after FCI (Fig. 7, lanes 2, 4, and 6 of p-Jak2 and p-Stat5; Fig. $8 B$ and $C$ ). When compared with the vehicle-treated FCI group, Epo treatment $(1000 \mathrm{U} / \mathrm{kg})$ did not significantly affect EpoR expression from 1 to $7 \mathrm{~d}$ (Fig. 7, lanes $3,5,7$; Fig. $8 A$ ) but prevented the decrease in p-Jak2 or p-Stat5 expression at 1 and $3 \mathrm{~d}$ (Fig. 7, lanes 3, 5; Fig. 8B and $C$ ). Moreover, it caused a marked increase in Bcl-xL expression $1 \mathrm{~d}$ (Fig. 7, lane 3; Fig. 8D) after FCI $(p<0.05$; ANOVA followed by Fisher's post hoc test). However, NF- $\kappa$ B expression in the cortex was not altered by FCI or Epo treatment from 


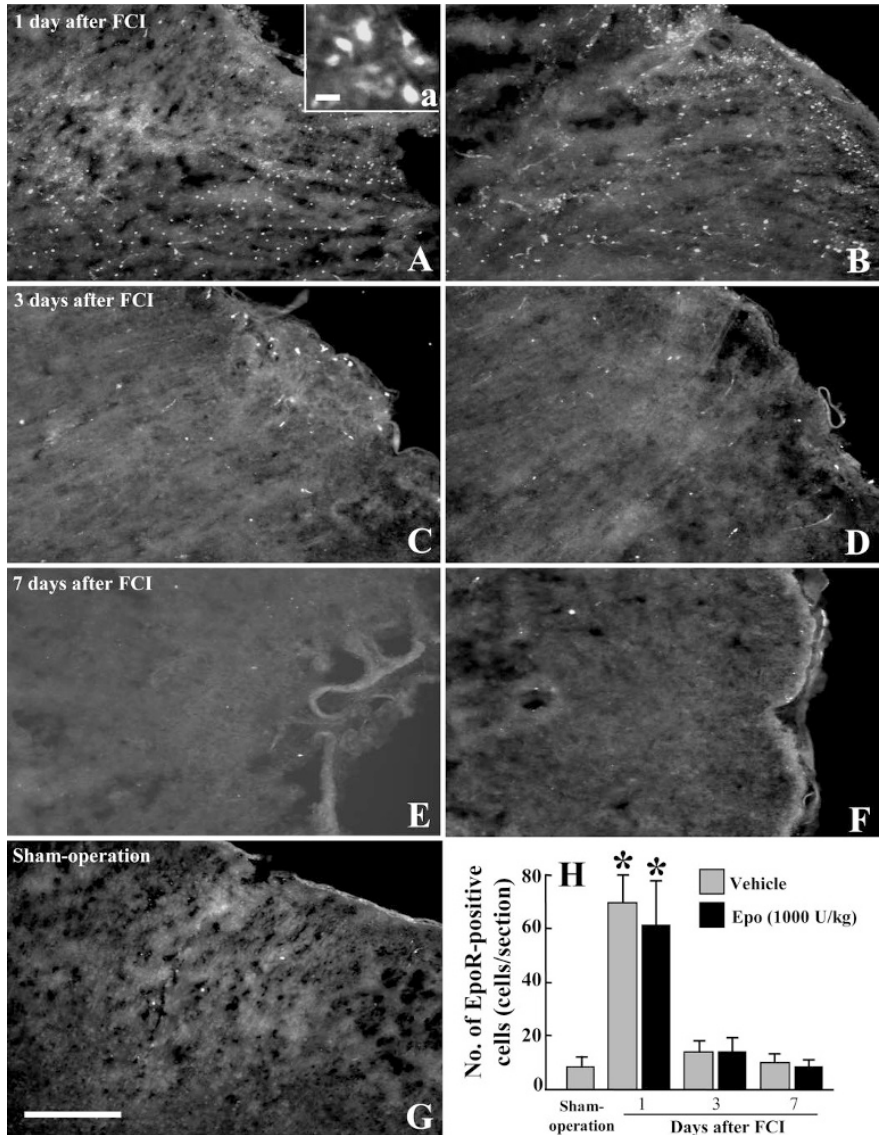

Figure 6. Immunoreactivity of cortical EpoR. $(A, C$, and $E)$ FCI pups that were treated with vehicle. (a) Magnification of EpoR-positive cells in $A$. ( $B, D$, and $F$ ) FCI pups that were treated with Epo $(1000 \mathrm{U} / \mathrm{kg})$. $(G)$ Sham-operated animals that were treated with vehicle. $(H)$ Number of EpoR-positive cells in the cortex of sham-operated and FCI pups. Epo $(1000 \mathrm{U} / \mathrm{kg})$ had no significant effect on EpoR expression in the ischemic cortex from 1 to $7 \mathrm{~d}$ after FCI $(H)$. Values in $H$ are mean $\pm \mathrm{SD}$ ( $n=4$ for each time point in each group). ${ }^{*} p<$ 0.01 vs sham-operated pups. Bar $=0.2 \mathrm{~mm}$.

1 to $7 \mathrm{~d}$ after FCI (Fig. 7, lanes 2-7; Fig. 8E). These results suggest that exogenous Epo administration did not alter the FCI-induced transient up-regulation of EpoR expression in the ischemic cortex from 1 to $7 \mathrm{~d}$ after FCI; however, Epo activated p-Jak2, p-Stat5, and Bcl-xL at 1 and $3 \mathrm{~d}$ after FCI.

\section{DISCUSSION}

Numerous studies in adult animals demonstrate that treatment with Epo attenuates brain injury in hypoxia, transient forebrain ischemia, or FCI $(5,6,9-10)$. In neonatal animals, Epo has been shown to reduce neurotoxicity of $N$-methyl-Daspartate receptor antagonists (12) and prevent brain injury in a P7 hypoxic-ischemic rat model $(13,14,28)$ when the first dose is given before producing the injury. There are two important differences between our current study and previous ones. One important difference is that in this study, Epo was applied after FCI, whereas previous studies involved Epo pretreatment before the insult. The other important difference is that the cerebral insult in the hypoxic-ischemic model is different from that in our FCI model. The current FCI model induces a focal ischemic stroke in the region supplied by the MCA and is

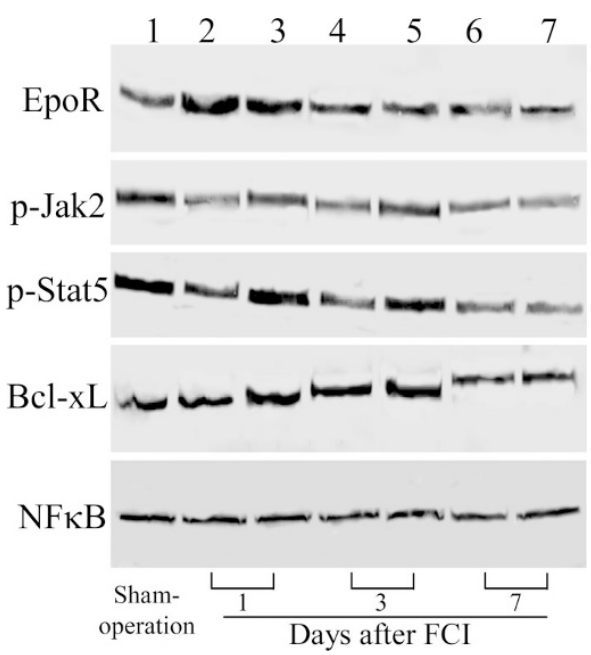

Figure 7. Western blot staining bands of EpoR, p-Jak2, p-Stat5, Bcl-xL, and $N F-\kappa B$ in the cortex at different times after FCI. Lane 1, sham-operated animals; lanes 2, 4, and 6, vehicle-treated FCI pups; lanes 3, 5, and 7, Epo-treated pups $(1000 \mathrm{U} / \mathrm{kg})$. Epo treatment did not affect the FCI-induced transient increase in intensity of EpoR-positive bands at $1 \mathrm{~d}$ (lanes 2 and 3) but prevented the FCI-induced decline in intensity of p-Jak2 (lanes 2, 4, and 6) and p-Stat5 (lanes 2, 4, and 6) immunoreactive bands at 1 and $3 \mathrm{~d}$ after FCI. Epo treatment also caused an increase in intensity of Bcl-xL immunoreactive bands $1 \mathrm{~d}$ after FCI (lane 3); however, it did not cause any alteration in the expression of NF- $\kappa \mathrm{B}$ (lanes 3, 5, and 7).

relevant for future studies given that neonatal focal cerebral insults are more common than previously recognized $(34,35)$. The present study in this FCI model in P7 rat pups demonstrates that Epo administered exogenously after the injury significantly reduces the mean infarct area, the mean infarct volume, and the number of TUNEL-positive cells in the ipsilateral ischemic cortex in a dose-dependent manner. Therefore, this study provides more practical meaning to Epo treatment for stroke in human neonates.

In the current experiments, we focused only on the effects of Epo on infarct size at 1 and $3 \mathrm{~d}$ after FCI by using TTC staining, which is an optimal method for identification of cerebral infarct (36). However, infarct size has been shown to evolve continually after $3 \mathrm{~d}$ of brain insult in many stroke models (37). Therefore, it is not clear whether the neuroprotective effects of Epo at 1 and $3 \mathrm{~d}$ after FCI are caused by reducing infarct size, inhibiting infarct expansion, or both. A recent report has shown that Epo administration at a single dose immediately after the hypoxia period significantly improves long-term spatial memory deficits at $20 \mathrm{wk}$ and reduces the infarct volume at $21 \mathrm{wk}$ after hypoxia-ischemia in P7 rats (38). More important, the brains in the Epo-treated animals show a slight hypotrophy of the ischemic hemisphere, whereas the brains in the saline-treated animals exhibit a severe atrophy and cortical cavities at $21 \mathrm{wk}$ after hypoxia-ischemia (38). In addition, our ongoing experiments indicate that Epo causes a significant reduction in the infarct area and volume at 6 and 12 wk after FCI (unpublished data). These results suggest that exogenous Epo treatment has a long-term neuroprotection on the developing brain against injury and that its effects may be caused not only by delaying infarct expansion but also by reducing infarct size. 


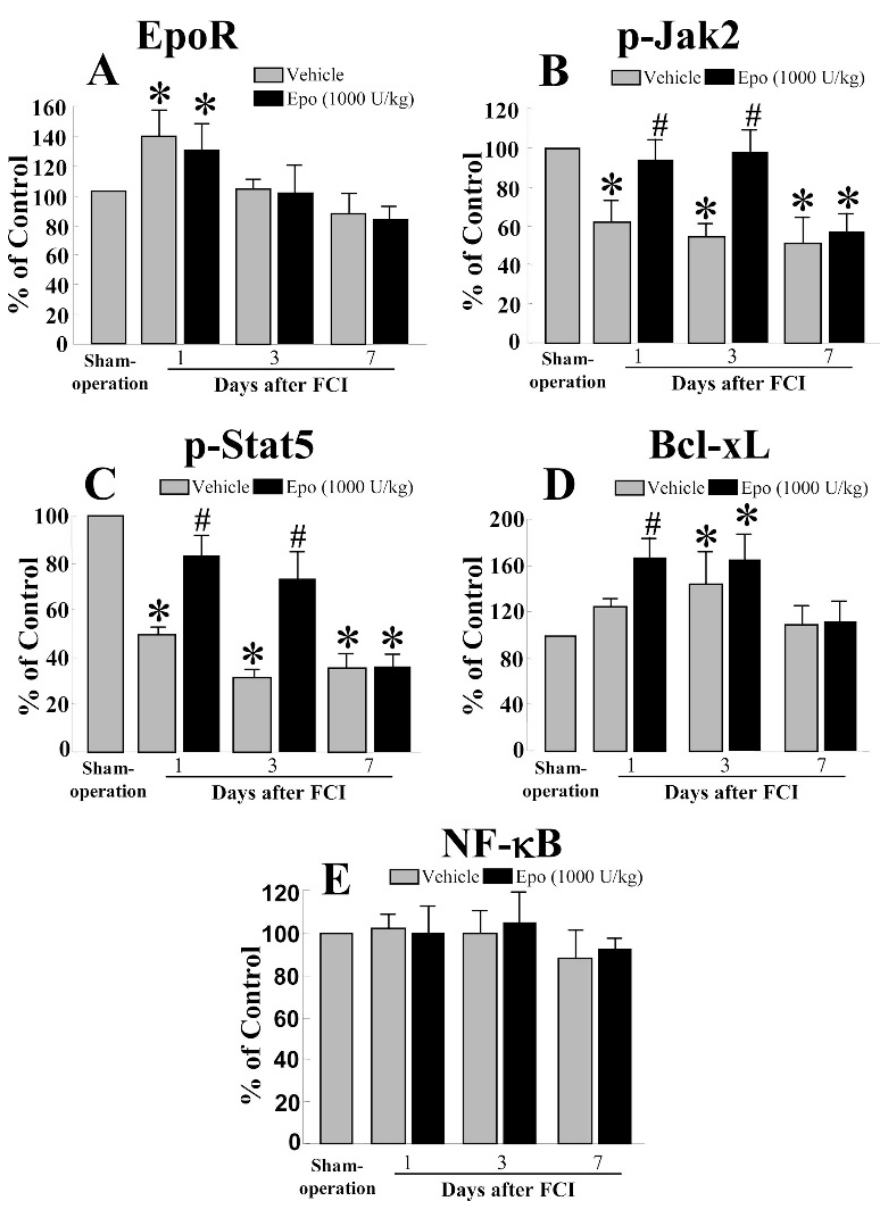

Figure 8. Densitometric analyses of EpoR, p-Jak2, p-Stat5, Bcl-xL, and $\mathrm{NF}-\kappa \mathrm{B}$ immunoreactive bands in cortices of sham-operated and $\mathrm{FCI}$ rat pups. Epo treatment (1000 U/kg) had no significant effect on EpoR expression in the ischemic cortex but caused significant increases in the expression of p-Jak2 and p-Stat5 at 1 and $3 \mathrm{~d}$ and in the expression of Bcl-xL at $1 \mathrm{~d}$ after FCI compared with the corresponding vehicle-treated FCI group. The data are obtained from four separate rats. Each bar represents mean \pm SD percentage change from values in the sham-operated rats. ${ }^{*} p<0.05 v s$ the value of sham-operated rats; \#p $<0.05$ vs the value of the corresponding vehicletreated FCI rats.

The body size of rats that underwent FCI surgery was significantly decreased compared with sham-operated rats. Ligation of the ECA is necessary in this FCI model and may have affected swallowing functions, resulting in less weight gain during the first postsurgical week in all pups that underwent FCI. A similar finding has been reported in adult rats with FCI (39). However, it is unlikely that this is a significant confounder to the significant differences in outcomes noted between Epo- and vehicle-treated rats, both of which underwent the FCI surgery and had similar decreases in weight gain compared with sham-operated rats. Nonetheless, this is a weakness of the model when comparing outcomes with shamoperated subjects.

Endogenous Epo may act as a neuroprotectant in the brain $(1,3)$. Indeed, Sakanaka et al. (5) demonstrated that intraventricular infusion of a soluble EpoR, which can neutralize endogenous Epo, caused neuronal death in the hippocampus of gerbils that were subjected to a mild ischemia that did not result in neuronal damage by itself. This result was confirmed by an observation that neutralization of endogenous Epo exacerbated neuronal injury in a transient global retina ischemic model (40). Furthermore, Shingo et al. (41) demonstrated that hypoxia-induced endogenous Epo may promote the production of neuronal progenitors after hypoxia. In the current experiments, we found that exogenously administered Epo after focal ischemic insult significantly reduced the infarct area, the infarct volume, and the number of TUNEL-positive cells in the ischemic cortex. These results suggest that endogenous Epo may be a protective agent for brains against cerebral ischemia in vivo.

The important issue to be addressed is whether the neuroprotective effects of Epo are initially triggered by its binding to its receptor. We did not detect any significant alteration in EpoR expression in the ischemic cortex from 1 to $7 \mathrm{~d}$ after focal ischemic insult in the Epo-treated pups compared with vehicle-treated pups. This issue is consistent with the findings that Epo treatment does not alter EpoR mRNA levels in a neurotoxic model (12) and that Epo application for $3 \mathrm{~d}$ does not down-regulate EpoR in a neonatal hypoxic-ischemic model (28). Recent data have also shown that carbamylated Epo or certain Epo mutants do not bind to the classical EpoR, but these Epo mutants were neuroprotective in vitro and in vivo (42). Therefore, the neuroprotective effect of exogenous Epo administration may not down-regulate the ischemia-induced up-regulation of EpoR but seems to restore endogenous Epo signaling. However, further experiments are needed to prove whether Epo binds to its receptor within the first $24 \mathrm{~h}$ after FCI and hence prevents the need for up-regulation of EpoR in the subsequent days after the initial $24 \mathrm{~h}$ of FCI and exogenous Epo administration.

The precise molecular mechanism underlying the neuroprotective effects of Epo has not been completely elucidated. Epo may act at multiple levels, including its antiapoptotic mechanisms. In nonneuronal cells, numerous pieces of evidence indicate that the antiapoptotic effects of Epo are mediated by activating Jak2, leading to tyrosine phosphorylation of the Stat5 and the up-regulation of antiapoptotic genes $(23,24)$. Recently, this Epo-mediated molecular signaling pathway was also established in neurons. Epo has been shown to protect hippocampal neurons from ischemic neuronal damage through activation of Jak2 (43) and induce phosphorylation of Stat5 in rat hippocampal neurons (44). In addition, Campana and Myers (45) reported that systemic administration of Epo reduces dorsal root ganglion apoptosis by activating p-Jak2 within $1 \mathrm{~d}$ after L5 spinal nerve crush. Furthermore, Digicaylioglu and Lipton (25) demonstrated that Epo prevents cultured cerebrocortical neuronal death by triggering Jak2 signaling pathways. More important, the current experiments indicated that Epo significantly activates p-Jak 2 and p-Stat 5 at 1 and $3 \mathrm{~d}$ and causes a significant increase in downstream cellular neuroprotective gene Bcl-xL $1 \mathrm{~d}$ after FCI in the neonatal brains. Epo treatment did not alter the expression of NF- $\kappa \mathrm{B}$, which has been shown to be activated by Epo treatment in cultured cerebrocortical neurons (25). However, the present results cannot exclude a possibility that Epo treatment may activate NF- $\kappa$ B's transcriptional activating function. This evidence suggests that Epo enhances neuronal survival possibly through 
activation of Jak2-Stat5 and the subsequent downstream cellular neuroprotective genes such as Bcl-xL.

In conclusion, the findings of this study show that Epo given after FCI protects the neonatal brain against FCI insults and attenuates the effects of neonatal cerebral stroke in neonatal rats with FCI, providing more practical meaning to Epo treatment for stroke in human neonates. Furthermore, the findings that exogenous Epo activated p-Jak2, p-Stat5, and Bcl-xL at 1 and $3 \mathrm{~d}$ after FCI provide insight regarding the molecular mechanisms involved in Epo neuroprotection in the developing brain.

\section{REFERENCES}

1. Dame C, Juul SE, Christensen RD 2001 The biology of erythropoietin in the central nervous system and its neurotrophic and neuroprotective potential. Biol Neonate 79:228-235

2. Buemi M, Cavallaro E, Floccari F, Sturiale A, Aloisi C, Trimarchi M, Corica F, Frisina N 2003 The pleiotropic effects of erythropoietin in the central nervous system. J Neuropathol Exp Neurol 62:228-236

3. Fisher JW 2003 Erythropoietin: physiology and pharmacology update. Exp Biol Med 228:1-14

4. Morishita E, Masuda S, Nagao M, Yasuda Y, Sasaki R 1997 Erythropoietin receptor is expressed in rat hippocampal and cerebral cortical neurons, and erythropoietin prevents in vitro glutamate-induced neuronal death. Neuroscience 76:105-116

5. Sakanaka M, Wen TC, Matsuda S, Masuda S, Morishita E, Nagao M, Sasaki R 1998 In vivo evidence that erythropoietin protects neurons from ischemic damage. Proc Natl Acad Sci USA 95:4635-4640

6. Bernaudin M, Marti HH, Roussel S, Divoux D, Nouvelot A, MacKenzie ET, Petit E 1999 A potential role for erythropoietin in focal permanent cerebral ischemia in mice. J Cereb Blood Flow Metab 19:643-651

7. Sinor AD, Greenberg DA 2000 Erythropoietin protects cultured cortical neurons, but not astroglia, from hypoxia and AMPA toxicity. Neurosci Lett 290:213-215

8. Siren AL, Fratelli M, Brines M, Goemans C, Casagrande S, Lewczuk P, Keenan S, Gleiter C, Pasquali C, Capobianco A, Mennini T, Heumann R, Cerami A, Ehrenreich H, Ghezzi P 2001 Erythropoietin prevents neuronal apoptosis after cerebral ischemia and metabolic stress. Proc Natl Acad Sci USA 98:4044-4049

9. Brines ML, Ghezzi P, Keenan S, Agnello D, de Lanerolle NC, Cerami C, Itri LM, Cerami A 2000 Erythropoietin crosses the blood-brain barrier to protect against experimental brain injury. Proc Natl Acad Sci USA 97:10526-10531

10. Wen TC, Sadamoto Y, Tanaka J, Zhu PX, Nakata K, Ma YJ, Hata R, Sakanaka M 2002 Erythropoietin protects neurons against chemical hypoxia and cerebral ischemic injury by up-regulating Bcl-xL expression. J Neurosci Res 67:795-803

11. Solaroglu I, Solaroglu A, Kaptanoglu E, Dede S, Haberal A, Beskonakli E, Kilinc K 2003 Erythropoietin prevents ischemia-reperfusion from inducing oxidative damage in fetal rat brain. Childs Nerv Syst 19:19-22

12. Dzietko M, Felderhoff-Mueser U, Sifringer M, Krutz B, Bittigau P, Thor F, Heumann R, Buhrer C, Ikonomidou C, Hansen HH 2004 Erythropoietin protects the developing brain against N-methyl-D-aspartate receptor antagonist neurotoxicity. Neurobiol Dis 15:177-187

13. Aydin A, Genc K, Akhisaroglu M, Yorukoglu K, Gokmen N, Gonullu E 2003 Erythropoietin exerts neuroprotective effect in neonatal rat model of hypoxicischemic brain injury. Brain Dev 25:494-498

14. Kumral A, Baskin H, Gokmen N, Yilmaz O, Genc K, Genc S, Tatli MM, Duman N, Ozer E, Ozkan H 2004 Selective inhibition of nitric oxide in hypoxic-ischemic brain model in newborn rats: is it an explanation for the protective role of erythropoietin? Biol Neonate 85:51-54

15. Levine S 1960 Anoxic-ischemic encephalopathy in rats. Am J Pathol 36:1-17

16. Rice JE 3rd, Vannucci RC, Brierley JB 1981 The influence of immaturity on hypoxic-ischemic brain damage in the rat. Ann Neurol 9:131-141

17. Koelfen W, Freund M, Varnholt V 1995 Neonatal stroke involving the middle cerebral artery in term infants: clinical presentation, EEG and imaging studies, and outcome. Dev Med Child Neurol 37:204-212

18. Lynch JK, Hirtz DG, DeVeber G, Nelson KB 2002 Report of the National Institute of Neurological Disorders and Stroke workshop on perinatal and childhood stroke. Pediatrics 109:116-123
19. Mader I, Schoning M, Klose U, Kuker W 2002 Neonatal cerebral infarction diagnosed by diffusion-weighted MRI: pseudonormalization occurs early. Stroke 33:1142-1145

20. Juul SE, Stallings SA, Christensen RD 1999 Erythropoietin in the cerebrospinal fluid of neonates who sustained CNS injury. Pediatr Res 46:543-547

21. Wen TC, Rogido M, Gressens P, Sola A 2004 A reproducible experimental model of focal cerebral ischemia in the neonatal rat. Brain Res Brain Res Protoc 13:76-83

22. Wen TC, Rogido M, Genetta T, Sola A 2004 Permanent focal cerebral ischemia activates erythropoietin receptor in neonatal rat brain. Neurosci Lett 355:165-168

23. Cattaneo E, Conti L, De-Frajac 1999 Signalling through the JAK-STAT pathway in the developing brain. Trends Neurosci 22:365-369

24. Socolovsky M, Fallon AE, Wang S, Brugnara C, Lodish HF 1999 Fetal anemia and apoptosis of red cell progenitors in Stat5a-/-5b-/- mice: a direct role for Stat5 in Bcl-X(L) induction. Cell 98:181-191

25. Digicaylioglu M, Lipton SA 2001 Erythropoietin-mediated neuroprotection involves cross-talk between Jak2 and NF-kB signalling cascades. Nature 412:641-647

26. Wang CY, Mayo MW, Korneluk RG, Goeddel DV, Baldwin AS Jr 1998 NF-kB antiapoptosis: induction of TRAF1 and TRAF2 and c-IAP1 and c-IAP2 to suppress caspase- 8 activation. Science 281:1680-1683

27. Pettmann B, Henderson CE 1998 Neuronal cell death. Neuron 20:633-647

28. Sun Y, Zhou C, Polk P, Nanda A, Zhang JH 2004 Mechanisms of erythropoietininduced brain protection in neonatal hypoxia-ischemia rat model. J Cereb Blood Flow Metab 24:259-270

29. Wen TC, Tanaka J, Peng H, Desaki J, Matsuda S, Maeda N, Fujita H, Sato K, Sakanaka M 1998 Interleukin 3 prevents delayed neuronal death in the hippocampal CA1 field. J Exp Med 188:635-649

30. Laemmli UK 1970 Cleavage of structural proteins during the assembly of the head of bacteriophage T4. Nature 227:680-685

31. Towbin H, Staehelin T, Gordon J 1979 Electrophoretic transfer of proteins from polyacrylamide gels to nitrocellulose sheets: procedure and some applications. Proc Natl Acad Sci USA 76:4350-4354

32. Kira M, Tanaka J, Sobue K 1995 Caldesmon and low Mr isoform of tropomyosin are localized in neuronal growth cones. J Neurosci Res 40:294-305

33. Tanaka J, Fujita H, Matsuda S, Toku K, Sakanaka M, Maeda N 1997 Glucocorticoidand mineralocorticoid receptors in microglial cells: the two receptors mediate differential effects of corticosteroids. Glia 20:23-37

34. Rademakers RP, van der Knaap MS, Verbeeten B Jr, Barth PG, Valk J 1995 Central cortico-subcortical involvement: a distinct pattern of brain damage caused by perinatal and postnatal asphyxia in term infants. J Comput Assist Tomogr 19:256-263

35. Volpe JJ 2001 Perinatal brain injury: from pathogenesis to neuroprotection. Ment Retard Dev Disabil Res Rev 7:56-64

36. Joshi CN, Jain SK, Murthy PS 2004 An optimized triphenyltetrazolium chloride method for identification of cerebral infarcts. Brain Res Brain Res Protoc 13:11-17

37. Lipton P 1999 Ischemic cell death in brain neurons. Physiol Rev 794:1431-1568

38. Kumral A, Uysal N, Tugyan K, Sonmez A, Yilmaz O, Gokmen N, Kiray M, Genc S, Duman N, Koroglu TF, Ozkan H, Genc K 2004 Erythropoietin improves long-term spatial memory deficits and brain injury following neonatal hypoxia-ischemia in rats. Behav Brain Res 153:77-86

39. Dittmar M, Spruss T, Schuierer G, Horn M 2003 External carotid artery territory ischemia impairs outcome in the endovascular filament model of middle cerebral artery occlusion in rats. Stroke 34:2252-2257

40. Junk AK, Mammis A, Savitz SI, Singh M, Roth S, Malhotra S, Rosenbaum PS, Cerami A, Brines M, Rosenbaum DM 2002 Erythropoietin administration protects retinal neurons from acute ischemia-reperfusion injury. Proc Natl Acad Sci USA 99:10659-10664

41. Shingo T, Sorokan ST, Shimazaki T, Weiss S 2001 Erythropoietin regulates the in vitro and in vivo production of neuronal progenitors by mammalian forebrain neural stem cells. J Neurosci 21:9733-9743

42. Leist M, Ghezzi P, Grasso G, Bianchi R, Villa P, Fratelli M, Savino C, Bianchi M, Nielsen J, Gerwien J, Kallunki P, Larsen AK, Helboe L, Christensen S, Pedersen LO, Nielsen M, Torup L, Sager T, Sfacteria A, Erbayraktar S, Erbayraktar Z, Gokmen N, Yilmaz O, Cerami-Hand C, Xie QW, Coleman T, Cerami A, Brines M 2004 Derivatives of erythropoietin that are tissue protective but not erythropoietic. Science 305:239-242

43. Kawakami M, Sekiguchi M, Sato K, Kozaki S, Takahashi M 2001 Erythropoietin receptor-mediated inhibition of exocytotic glutamate release confers neuroprotection during chemical ischemia. J Biol Chem 276:39469-39475

44. Marti HH 2004 Erythropoietin and the hypoxic brain. J Exp Biol 207:3233-3242

45. Campana WM, Myers RR 2003 Exogenous erythropoietin protects against dorsal root ganglion apoptosis and pain following peripheral nerve injury. Eur J Neurosci 18:1497-1506 